\title{
Taze ve Sulandırımamış Sperma ile Yapay Tohumlanan Yerli Koyunların Döl Verim Özellikleri
}

\section{Kadir KIRK ${ }^{* 1}[\mathbb{C}$}

\author{
${ }^{1}$ Yüzüncü Yıl Üniversitesi Ziraat Fakültesi Zootekni Bölümü, 65080, Kampüs/Tuşba-Van
}

Öz: Bu araştırmada, 102 baş Norduz ve 587 baş İvesi kullanılarak, taze ve sulandırılmamış sperma ile yapay tohumlama döl verim parametreleri belirlenmiştir. Sabah, akşam ve toplam kızgınlık tespitleri sırası ile; Norduz'larda $47 \pm 0.23$ baş (\% 47.96) - $34 \pm 0.16$ baş (\% 34.69) ve $81 \pm 0.20$ baş (\% 82.65), ivesi'lerde $359 \pm 0.97$ baş (\% 61.58) $-197 \pm 0.63$ baş (\% 33.79) ve $556 \pm$ 0.8 baş (\% 95.37) belirlenmiştir. Hiç kızgınlık göstermeyen, Norduz ve İvesi'ler sırası ile; $17 \pm 0.18$ baş (\% 17.35) ve $27 \pm 0.21$ baş (\% 4.63) belirlenmiştir. Kızgınlık tespitinden, 11.0 saat sonra, serviks ağzına (os cervical) $0.3 \mathrm{ml} / \mathrm{baş} \mathrm{doz} \mathrm{taze} \mathrm{ve}$ sulandırımamış sperma ile yapay tohumlama yapılmıştır. Döl verim parametreleri ortalamaları, Norduz ve ìvesilerde sırası ile; gebelik süresi $157.6 \pm 3.38$ - $153.1 \pm 1.81$ gün, tek doğum $51 \pm 1.17$ baş (\% 62.97) - 387 \pm 1.13 baş (\% 69.60), ikiz doğum

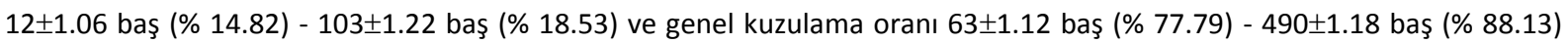
olarak belirlenmiştir. Taze ve sulandırımamış sperma ile yapay tohumlama döl verim parametreleri bakımından, İvesi toklular, Norduz koyunlarından, istatistiki olarak önemli düzeyde yüksek bulunmuştur ( $P \leq 0.01)$. Buna göre, İvesi'lerin yüksek adaptasyon, süt ve döl verim özellikleri ile, yerli koyun ırklarının ıslahında, etkin damızlık materyali olarak kullanılabilecekleri söylenebilir.

Anahtar Kelimeler: İvesi, norduz, kızgınlık, döl verimi

\section{Fertility Characteristics of Domestic Sheep Artificial Inseminated with Fresh and Undiluted Semen}

\begin{abstract}
In this study, fertilization parameters of 102 head Norduz and 583 head Awassi with fresh and undiluted semen by artificial insemination were determined. Morning, evening and total estrus detection were respectively; In the Norduz, $47 \pm 0.23$ head (47.96\%) - 34 \pm 0.16 head (34.69\%) and $81 \pm 0.20$ head (82.65\%), In the Awassi, $359 \pm 0.97$ head (61.58 \%) - $197 \pm 0.63$ head (33.79\%) and $556 \pm 0.8$ head (95.37\%). Those who show no estrus in Norduz and Awassi were respectively; $17 \pm 0.18$ head and (17.35\%) - $27 \pm 0.21$ head (4.63\%). After 11.0 hours of estrus detection artificial insemination with fresh and undiluted semen of $0.3 \mathrm{ml} /$ head dose into the cervical mouth (os cervical) were performed. Mean yield parameters, Norduz and Awassi in respectively; the length of pregnancy 157.6 $\pm 3.38-153.1 \pm 1.81$ day, the single lambing $51 \pm 1.17$ head (62.97\%) - 387 \pm 1.13 head (69.60 \%), the twins lambing $12 \pm 1.06$ head (14.82 \%) - $103 \pm 1.22$ head (18.53 $\%)$, and the total lambing head and rate on $63 \pm 1.12$ head (77.79\%) - 490 \pm 1.18 head (88.13\%) rate were determined. In terms of fertilization parameters of artificial insemination with fresh and undiluted semen, Awassi yearling were significantly higher than Norduz ewe $(P \leq 0.01)$. According to this, it can be said that Awassi yearlings can be used as effective breeding material in the breeding of domestic sheep breeds with their high adaptability, milk and progeny yield characteristics.
\end{abstract}

Keywords: Awassi, norduz, estrus, reproductive characteristics

GiRiş

Yerli koyun yetiştiriciliği, Anadolu'nun ve kırsal bölgelerinin en önemli, hayvansal üretim, tüketim ve gelir kaynağıdır. Bölgelerin tarımsal faaliyetleri dikkate alındığında, koyun yetiştiriciliği hayvansal üretim içinde en önemli paya sahiptir (Kingwell ve ark., 1995; Gürsoy ve ark., 1998). Bu durum mevcut koyun popülasyonlarının verim özellikleri ile yakın ilişkilidir. Bölge küçükbaş hayvan yetiştiriciliği incelendiğinde, koyun yetiştiriciliği, bölge koşullarındaki döl, süt, et vb. verim özelliklerinin adaptasyonu, bölge yetiştiricisinin ırk ve popülasyona özgü tercihini oluşturmuştur. Yetiştirici koşullarında mevsimsel koç katımı koyun popülasyonlarının döl verimi ve dolayısı ile süt, et vb. diğer verimlerini doğrudan belirlemektedir (Berkyürek ve İzgür, 1992). Kırsal bölge mera veya anız koşullarında koç katımı genellikle serbest usulde 1/20-55 erkek dişi oranında koç katılmaktadır. Bu yöntem ile yıl boyu koç bakım maliyeti ve dölleme gücü belli olmayan koç riski ve koçtan kaynaklanacak kısırlık riski gibi faktörler serbest koç katımının sürü ve popülasyonların döl verimlerinin düşmesine neden olduğu yerli ve yabancı araştırıcılar tarafından da bildirilmiştir (Kaymakçı ve Sönmez, 1989; Cappelletti ve ark., 2006). Birçok bilimsel çalışmada, damızlık değeri ve üreme değerleri bilinen koçların, popülasyonların ıslahında önemli etkinliğe sahip olduğu bildirilmektedir. Damızlık değeri belirlenmiş ve yüksek damızlık değere sahip olduğu bilinen koçların, birim popülasyonların verim özelliklerini generasyonlar boyu arttırdığına dair birçok çalışma bulunmaktadır (Beilby ve ark., 2009; Kırk, 1994; Kırk, 2001; Paulenza ve ark., 2005). Ceylanpınar TiM koşullarında taze ve sulandırılmamış sperma ile yapay tohumlanan İvesi dişi toklu sürülerinde, 2191-3050 baş arasında, 1992-1999 yılları arasında taze ve sulandırılmamış sperma ile yapılan yapay tohumlamalardan \% 60.50-81.63 oranında döl verimi elde edildiğini, yine aynı koşullarda 2.0-6.5 yaşlı 1876-2263 baş İvesi koyununun

Sorumlu Yazar: candemkkirk@gmail.com

Geliş Tarihi: 22 Şubat 2019

Kabul Tarihi: 27 Mayıs 2019 
yapay tohumlanmasından \% 77.05-88.06 oranlarında döl verimi elde edildiği bildirilmiştir (Gürsoy ve ark., 2001; Paulenza ve ark., 2003). Yerli koyun ırkları, üreme özellikleri bakımından bölge koşullarına adapte olmuş popülasyonlardır. Koç altı koyun ile doğuran koyun sayısı arasındaki fark sürü ve popülasyonun kuzulama oranı ve üreme verimini ortaya koymaktadır. Bu sonuç, birçok yerli ve yabancı literatürde aynı bilimsel gerçeklerle desteklenmektedir. Ekstansif koyun yetiştiriciliğinde yerli koyun ırklarında popülasyonların döl verim özellikleri genotip ve çevrenin etkisi ile mevcut fenotipik yapı ve verimi ortaya koymaktadır. Birçok küçükbaş hayvan ıslah, strateji ve programı, popülasyondaki genotipik üstünlüğü generasyonlar arası variyasyona aktarabilirse, işte o zaman, ıslahta genetik ilerleme sağlanabilir. Popülasyonda genotipik varyasyonun oluşması, doğal aşım yöntemleri ile gerçekleşemez, çünkü doğal aşım ile bir koç, genetik etkisini, aşım yaptığı dişinin dölleri kadar gösterir. Bu nedenle, ekstansif yetiştirici koşullarında, yerli koyun ırklarından oluşan sürülerin, saha koşullarında, döl verimi ile birlikte, süt ve et verimlerinin de arttırılması için, saha koşullarında taze sperma ile yapay tohumlanmaları gerekmektedir. Böylece damızlık değeri belirlenmiş bir koçun, genotipik etkisini, doğal aşıma oranla 10-12 kat daha fazla sayıda dişiyi tohumlayarak, genotipik etkisini döllerine aktaracaktır (Pollott ve ark., 1998; Santolariaa ve ark., 2015). Böylece, sürü ve popülasyonun döl verimleri artarken erkek materyalden ve koç katım sisteminden kaynaklanabilecek döl verimi kayıpları optimum düzeylere çekilecektir. Kırsal alan koşullarında koç katımı ile döl verimi doğrusal ilişkili olup elde edilecek döllerin sürü içindeki çağları ve verim özelliklerini doğrudan etkiler. Bu durum bölge koşullarında yapılan koyun yetiştiriciliğinin ekonomik olarak sürdürülebilirliğini doğrudan etkiler (Gürsoy ve ark., 2001).

$\mathrm{Bu}$ araştırmanın amacı, taze ve sulandırılmamış sperma ile yapay tohumlanan, Van ili ekstansif koşullarında yetiştirilen Norduz koyunu ve yarı-entansif koşullarda Ceylanpınar Tarım İşletmesi (TiM)'de yetiştirilen İvesi koyunlarında döl verim parametrelerin belirlenmesidir.

\section{MATERYAL VE YÖNTEM}

\section{Materyal}

$\mathrm{Bu}$ çalışmada hayvan materyali olarak; Van ili ekstansif yetiştirici koşullarında bulunan yaklaşık 5 yaşlı 98 baş koyun ve 4 baş koç olmak üzere toplam 102 baş Norduz (Şekil 1-2) ve Ceylanpınar Tarım İşletmesi (TiM) yarı-entansif koşullarında üretim sürülerinde bulunan yaklaşık 20 ay yaşlı 583 baş ívesi (Şekil 3-4) dişi toklu ve 4 baş koç olmak üzere toplam 587 baş İvesi'nin taze sperma ile yapay tohumlama sonuçları değerlendirilmiştir.

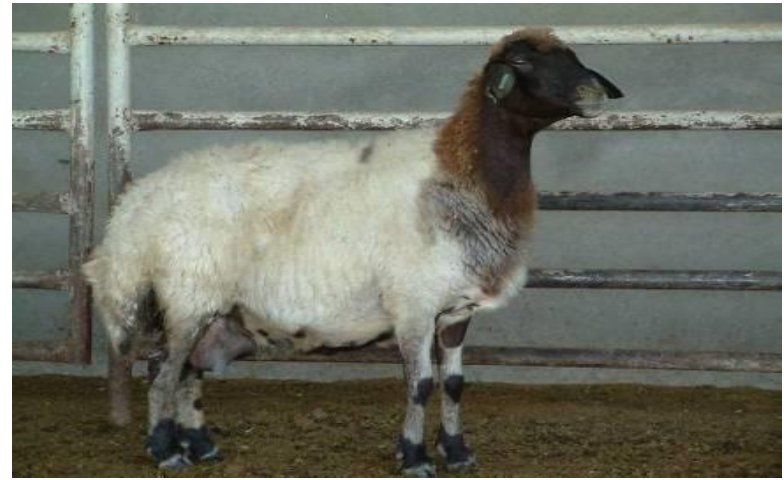

Şekil 1. Norduz koyunu

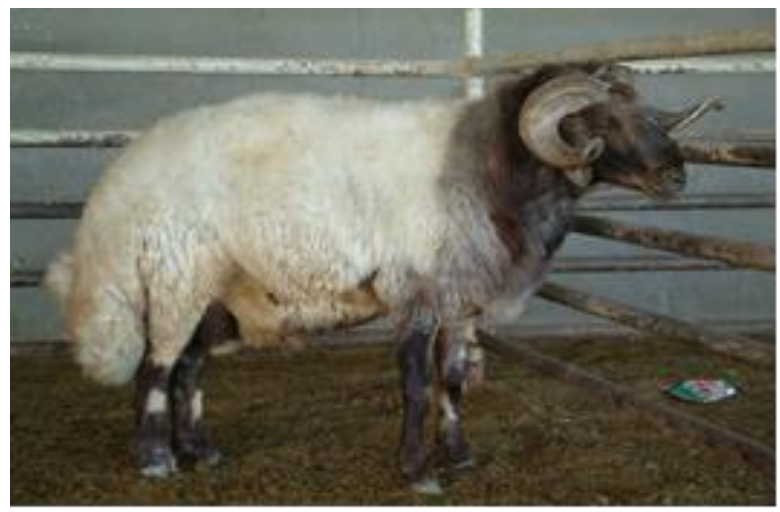

Şekil 2. Norduz koçu

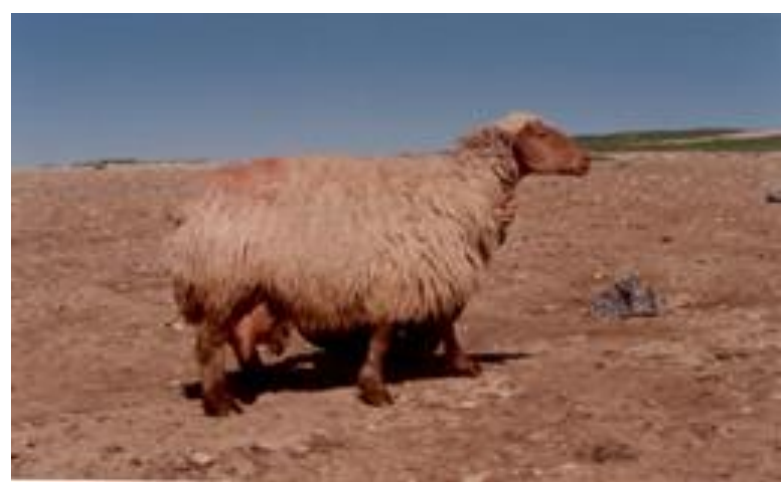

Şekil 3. İvesi koyunu

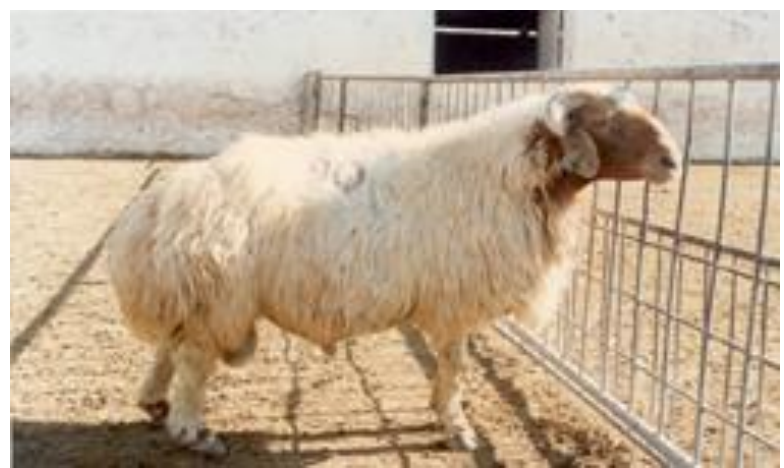

Şekil 4. İvesi koçu 


\section{Yöntem}

Araştırmanın, yapay tohumlama organizasyonundan doğum verilerinin alınmasına kadar tüm aşamaları Norduz'larda ekstansif koşullarda, İvesi'lerde ise yarı-entansif koşullarda uygulanmıştır. Sürü içinde işlem uygulanan koyunların tespitinde, sırt bölgelerine geçici boya ile işaretleme yöntemi kullanılmıştır. Her iki ırkta da sperma toplama işlemlerinde yapay vajen yöntemi kullanılmıştır. Sperma ejekülatı alınan koçların yapay tohumlamaya uygunluk testlerinde makro ve mikro spermatolojik özellik testi yöntemi uygulanmıştır (Kırk ve Gürsoy, 1995). Kızgın dişilerin belirlenmesinde $1 / 60$ oranında arama koçu yöntemi kullanılırken, kızgın olduğu belirlenenlerin yapay tohumlanmasında vaginal yöntem kullanılmıştır. Döl verimi parametrelerinin İstatistiki analizlerinde ise SAS-GLM 2014 prosedürü kullanılmıştır.

\section{BULGULAR VE TARTIŞMA}

\section{Bulgular}

Farklı bölgelerde yetiştirilen, farklı yaşlı koyun ırklarının, kızgınlık ve yapay tohumlama ve döl verim sonuçları belirlenmiştir. Buna göre; Yapay tohumlamada kullanılacak, yaklaşık 5 yaşı 4 baş Norduz koç ile, yaklaşık 20 ay yaşlı 4 baş İvesi koç, yaklaşık 15 gün süre ile yapay vajen eğitimine alınmıştır. Bu eğitim süresince, elde edilen ejekülatlar, makro ve mikro spermatolojik özellik testinden geçirilmiştir. $\mathrm{Bu}$ test sonucu, yapay tohumlamaya uygun olduğuna karar verilen koçların sperma ejekülatları, kızgın koyunların yapay tohumlamasında kullanılmıştır.

Norduz ve İvesi'lerde, kızgınlık tespitleri, sabah ve akşam olmak üzere günde iki defa yapılmıştır. Norduz'ların kızgınlık tespitlerinde, sabah $47 \pm 0.23$ baş \%47.96, akşam $34 \pm 0.16$ baş \%34.69 olmak üzere toplam $81 \pm 0.20$ baş $\% 82.65$ 'nin, kızgınlık gösterdiği belirlenmiştir (Çizelge 1). Farklı yaşlı Norduz koyunlarının, kızgınlık belirleme zamanlarına göre, sabah kızgınlık gösterenlerin sayı ve oranları, akşam kızgınlık gösterenlerin sayı ve oranlarına göre, istatistiki olarak, önemli düzeyde yüksek bulunmuştur $(P \leq 0.01)$. Bu durumun, koç etkileşiminin uyarıcı etkisinin zamana bağlı değişiminden kaynaklanabileceği söylenebilir. Çünkü iki kızgınlık belirleme zamanı arasındaki süre incelendiğinde, sabah kızgınlık tespitinde, son kızgınlık taraması ile sabah kızgınlık taraması arasında geçen süre, yaklaşık 12-14 saat sürerken, akşam kızgınlık taramasında ise, akşam kızgınlık taraması ile en son kızgınlık taraması arasında geçen süre ise yaklaşık, 5-6 saat olmaktadır. Bu nedenle, iki kızgınlık tespiti arasında geçen süre ile, kızgınlık tespitinde, kızgın olduğu belirlenen koyun sayısı arasında, kızgınlık tespiti süresince, koç ile birlikte bulundurmanın uyarıcı etki süresinin uzunluğu ile doğrusal bir ilişki olduğu söylenebilir. Bu durum, yerli ırkların kızgınlık düzeyleri ile ilgili olup, bazı ulusal ve uluslararası literatür ile uyum göstermektedir (Kırk ve Gürsoy, 1998; Paulenza ve ark., 2005).
Çizelge 1. Norduz Koyunlarında Kızgınlık Tespiti

\begin{tabular}{lll}
\hline Kızgınlık Tespitleri & $\mathbf{n}$ (baş) & Oran (\%) \\
\hline Sabah & $47 \pm 0.23$ & 47.96 \\
Akşam & $34 \pm 0.16$ & 34.69 \\
Toplam & $81 \pm 0.20$ & 82.65 \\
Hiç Kızgınlık Göstermeyen & $17 \pm 0.18$ & 17.35 \\
\hline
\end{tabular}

Aynı kızgınlık tespitlerinde Norduz koyunlarının $17 \pm 0.18$ başı (\% 17.35) ise hiç kızgınlık göstermediği belirlenmiştir. Hiç kızgınlık göstermeyen Norduz'ların sayı ve oranları istatistiki olarak önemli bulunmuştur. Ekstansif yetiştirme sistemine bağlı olarak yıl içinde, uzun süre koç ile karışık yetiştirme veya koç ile karışık farklı koyun sürüleri ile aynı ortak merayı kullanmaları sonucu gelişen, üremede gecikme problemleri veya ırka özgü mevsim dışı kızgınlık periyodu yaşan koyunlar gibi bir çok etkene bağlı, kızgınlık göstermeme sebeplerinden biri veya birkaçı olabilir. Bu grupta olan koyunların, geçici işaret boya ve kalıcı pedigri kayıt kontrolleri ile sürü içinde yakın takibe alınarak, bir sonraki mevsimde de benzer sonuçlara ulaşıldığında, bu gibi koyunların sürüden ayıklanmasının, sürünün döl verim etkinliğini arttırabileceğini söyleyebiliriz (Pollott ve ark., 1998; Kingwell ve ark., 1995). İvesi dişi tokluların kızgınlık tespitlerinde sabah kızgınlık gösterenler $359 \pm 0.97$ baş (\% 61.58) iken akşam kızgınlık gösterenler $197 \pm 0.63$ baş (\% 33.79) olmak üzere toplam kızgınlık gösteren $556 \pm 0.8$ baş (\% 95.37) olarak belirlenmiştir (Çizelge 2). Araştırmada kullanılan İvesi dişi toklular damızlıkta ilk defa kullanılan dişiler olup yaklaşık 5 yaşlı Norduz'larda olduğu gibi İvesi dişi toklularda da sabah kızgınlık gösterenler ile akşam kızgınlık gösterenler arasında istatistiki bakımdan, önemli düzeyde farklılık belirlenmiştir ( $\mathrm{P} \leq 0.01)$.

Çizelge 2. İvesi toklularında kızgınlık tespiti

\begin{tabular}{lcl}
\hline Kızgınlık Tespitleri & $\mathbf{n}$ (baş) & Oran (\%) \\
\hline Sabah & $359 \pm 0.97$ & 61.58 \\
Akşam & $197 \pm 0.63$ & 33.79 \\
Toplam & $556 \pm 0.8$ & 95.37 \\
Hiç Kızgınlık Göstermeyen & $27 \pm 0.21$ & 4.63 \\
\hline
\end{tabular}

Bu durum, Norduz'ların kızgınlık tespitlerinde olduğu gibi, kızgınlık tarama zamanları arasındaki süreye bağlı olarak koç etkileşiminin, zamana bağlı uyarıcı etkisinin iki kızgınlık tespiti arasında geçen sürenin, kızgınlığın uyarılmasına etkisinden kaynaklanabileceği söylenebilir (Anela ve ark., 2005; Halbert ve ark., 1990; Paulenza ve ark., 2003). Sabah ve akşam kızgınlık belirleme zamanı arasındaki süre yaklaşık 12-14 saat sürmektedir. Sabah kızgınlık tespitlerinin sayı ve oran olarak, akşam tespitlerinden yüksek çıkmasının nedeni ise, bu periyottaki karanlık süre daha uzun iken, akşam kızgınlık tespitlerinde ise, daha az sayı ve oranda kızgın dişi belirlenmiştir. İvesi dişi toklularda, yapılan kızgınlık tespitlerinde, hiç kızgınlık göstermeyen $27 \pm 0.21$ baş (\% 4.63) oranında İvesi dişi toklu belirlenmiştir. Bu durum 
damızlıkta ilk defa kullanılan İvesi dişi tokluların, yaklaşık 5 yaşlı Norduz koyunlarına göre istatistiki olarak önemli düzeyde düşük bulunmuştur $(P \leq 0.01)$. Üreme etkinliği bakımından mevsim dışı üreme özelliğine sahip İvesi'lerin Norduz'lar ve diğer yerli koyun ırklarına göre daha etkin ve düzenli kızgınlık göstermelerinden kaynaklandığı söylenebilir (Kingwell ve ark., 1995). Kızgınlık tespitlerinde, kızgın olduğu belirlenen Norduz ve İvesi dişiler, geçici boyama yöntemi ile işaretlenerek, kızgın dişi bölmelerinde yaklaşık 10-14 saat sınırsız kaba yem ve su koşullarında Çizelge 3. Yerli koyun ırklarının yapay tohumlama dağılımları bekletilerek kızgınlık tespitinden ortalama 10 saat sonra 0.3 $\mathrm{ml} /$ baş doz taze ve sulandırılmamış sperma ile serviks ağzına vaginal yöntem ile yapay tohumlanmışlardır. Yapay tohumlama programında kızgın olduğu sabah belirlenen Norduz koyun ve ivesi toklular, akşam tohumlamasına alınmışlardır (Çizelge 3). Akşam kızgınlık tespitleri yapılan Norduz koyun ve İvesi toklular ise, ertesi sabah yapay tohumlanmışlardır (Fisher 2004; Milán ve ark., 2011; Kırk ve Gürsoy 1995; Santolariaa ve ark., 2015; Wulster-Radcliffe ve ark., 2004).

\begin{tabular}{lllllll}
\hline & Norduz & & ivesi & & \multicolumn{2}{l}{ Toplam } \\
\hline Kızgınlık Tespitleri & $\mathbf{n}$ (baş) & Oran (\%) & $\mathbf{n}$ (baş) & Oran (\%) & n (baş) & Oran (\%) \\
\hline Sabah & $34 \pm 0.16$ & 34.69 & $197 \pm 0.63$ & 33.79 & $231 \pm 0.40$ & 36.26 \\
Akşam & $47 \pm 0.23$ & 47.96 & $359 \pm 0.97$ & 61.58 & $406 \pm 0.60$ & 63.74 \\
Toplam & $81 \pm 0.20$ & 82.65 & $556 \pm 0.8$ & 95.37 & $637 \pm 0.50$ & 100.00
\end{tabular}

Norduz ve İvesi'lerin sabah tohumlamasında sırası ile $34 \pm$ 0.16 baş (\% 34.69) ve $197 \pm 0.63$ baş (\% 33.79) olmak üzere her iki ırkta toplamda $231 \pm 0.40$ baş (\% 36.26) sayı ve oranda yapay tohumlama yapılmıştır. Akşam yapay tohumlamasında ise sırası ile $47 \pm 0.23$ baş (\% 47.96) sayı ve oranında Norduz ile, $359 \pm 0.97$ baş (\% 61.58) sayı ve oranında İvesi olmak üzere, akşam toplam $406 \pm 0.60$ baş (\% 63.74) sayı ve oranında yapay tohumlama yapılmıştır. Yapay tohumlama programında, genel toplamda koyunların tümü (637 \pm 0.50 baş ve $\% 100.00$ oranında) yapay tohumlanmıştır. Saha koşullarında uygulanan, genel yapay tohumlama programlarında, sabah yapay tohumlanan koyun sayısı, akşam yapay tohumlanan koyun sayısından düşük olarak belirlenmiştir. Bu değerlerin, kızgınlık tespitlerine bağlı olarak değişim gösterdiği söylenebilir (Donovan ve ark., 2004; Kırk, 2018; Pollott ve ark., 1998). Yapay tohumlaması tamamlanıp, pedigri kayıtları oluşturulan Norduz ve İvesi koyunlarının, doğum döneminde, gebelik süresi, tek doğum oranı, ikizlik oranı ve genel kuzulama oranı gibi döl verim parametreleri Çizelge 4 ve Çizelge 5'te sunulmuştur.

Çizelge 4. Norduzların döl verim özellikleri

\begin{tabular}{lcl}
\hline Döl verim özellikleri & $\mathbf{n}$ (baş) & Oran (\% ) \\
\hline Gebelik Süresi & $157.6 \pm 3.38$ gün & - \\
Tek doğum & $51 \pm 1.17$ baş & 62.97 \\
İkiz doğum & $12 \pm 1.06$ baş & 14.82 \\
Genel kuzulama & $63 \pm 1.12$ baş & 77.79 \\
\hline
\end{tabular}

Çizelge 5. İvesilerin döl verim özellikleri

\begin{tabular}{lcl}
\hline Döl verim özellikleri & Ortalama & Oran (\%) \\
\hline Gebelik Süresi & $153.1 \pm 1.81$ gün & - \\
Tek doğum & $387 \pm 1.13$ baş & 69.60 \\
İkiz doğum & $103 \pm 1.22$ baş & 18.53 \\
Genel kuzulama & $490 \pm 1.18$ baş & 88.13 \\
\hline
\end{tabular}

Araştırmada, Van ili koşullarındaki 5 yaşlı yapay tohumlanan Norduz koyunlarının döl verim parametreleri ortalamaları sırası ile; gebelik süresi $157.6 \pm 3.38$ gün, tek doğuran koyun sayısı $51 \pm 1.17$ baş ve oranı \% 62.97, ikiz doğuran koyun sayısı $12 \pm 1.06$ baş ve oranı \% 14.82 ile genel kuzulayan koyun sayısı $63 \pm 1.12$ baş ve genel kuzulama oranı $\% 77.79$ olarak belirlenmiştir. Benzer sonuçlar bazı araştırmacılar tarafından da bildirilmiştir (Anela ve ark., 2005;Gürsoy ve ark., 2001; Wulster-Radcliffe ve ark., 2004; Paulenza ve ark., 2003).

Araştırmada, Ceylanpınar TiM koşullarındaki 20 ay yaşlı yapay tohumlanan İvesi dişi tokluların döl verim parametreleri ortalamaları sırası ile; gebelik süresi $153.1 \pm$ 1.81 gün, tek doğuran koyun sayısı $387 \pm 1.13$ baş ve oranı $\%$ 69.60, ikiz doğuran koyun sayısı $103 \pm 1.22$ baş ve oranı \% 18.53 ile genel kuzulayan koyun sayısı $490 \pm 1.18$ baş ve genel kuzulama oranı \% 88.13 olarak belirlenmiştir. Bulgular literatür bildirişleri ile uyumlu bulunmuştur (Halbert ve ark., 1990; Kırk ve Gürsoy, 1995; Kingwell ark., 1995; Santolariaa ve ark., 2015). Araştırma parametreleri incelendiğinde, yaklaşık 5 yaşlı Norduz koyunlarının, ekstansif koşullardaki kızgınlık ve döl verim parametreleri, istatistiki olarak önemli düzeyde 20 ay yaşlı İvesi koyunlarının kızgınlık ve döl verim parametrelerinden düşük düzeyde bulunmuştur $(p \leq 0.01)$. Bu durum İvesi'lerin bilinen yüksek süt verim ve adaptasyon yetenekleri ile birlikte yüksek döl verim özellikleri ile yerli koyun ırklarının ıslahında damızlık materyal olarak etkin bir şekilde kullanılabileceklerini ortaya koymuştur.

\section{Tartışma}

$\mathrm{Bu}$ araştırma ile farklı bölgelerdeki, farklı ırk yerli koyunların, taze sperma ile yapay tohumlama sonuçları belirlenmiştir. Yerli koyun ırklarında farklı bölge ve farklı ırk koyunların kızgınlıklarının uyarılmasında her iki ırkta da sabah kızgınlık tespitlerinde kızgın olduğu belirlenen koyun sayı ve oranının, istatistiki olarak akşam kızgınlık gösteren koyun sayı ve oranından önemli düzeyde yüksek olduğu belirlenmiştir. İvesilerin, Norduz'lara göre istatistiki olarak önemli düzeyde, düzenli kızgınlık gösterdikleri belirlenmiştir. Norduz'ların döl verim oranı istatistiki olarak, 
İvesilerin döl verim oranından önemli düzeyde düşük bulunmuştur. Kızgınlık davranışında olduğu gibi, taze sperma ile, yapay tohumlama döl verim oranlarında da, İvesi'lerin, Norduz'lara göre yüksek döl verim kapasitesine sahip oldukları söylenebilir. Elde edilen üreme parametreleri incelendiğinde, henüz damızlıkta ilk defa kullanılan yaklaşık 20 ay yaşlı, İvesi dişi tokluların, kızgınlık tespiti, yapay tohumlama ve döl parametreleri bakımından, yaklaşık 5 yaşlı Norduz'ların kızgınlık ve döl verim parametrelerinden istatistiki olarak, önemli düzeyde yüksek belirlenmiştir. Bu durum İvesi'lerin bilinen yüksek süt verim ve adaptasyon yetenekleri ile birlikte, yüksek döl verim özellikleri ile de yerli koyun ırklarının ıslahında, damızlık materyal olarak etkin bir şekilde kullanılabileceğini göstermektedir.

\section{KAYNAKLAR}

Anela L, Kaabia M, Abrouga B, Alvareza M, Anela E, Boixoa JC, de la Fuenteb LF, Pazc P (2005) Factors influencing the success of vaginal and laparoscopic artificial insemination in churra ewes: a field assay. Theriogenology 63: 1235-1247.

Beilby KH, Grupen CG, Thomson PC, Maxwell WMC, Evans $G$, (2009) The effect of insemination time and sperm dose on pregnancy rate using sex-sorted ram sperm. Theriogenology 71: 829-835.

Cappelletti CA, Rozen FMB, De La Fuente Crespo LF, San Primitivo $F$ (2006) Extension factors for part-lactation in Churra sheep breed. Small Ruminant Research, 63(3):282-287.

Berkyürek T, İzgür ì (1992) Koyunlarda Kuzulamanın Kontrolü, Doğa, Tr.J. of Veterinary and Animal Sciences, 16:353-361.

Donovan A, Hanrahan JP, Kummen E, Duffy P, Boland MP (2004) Fertility in the ewe following cervical insemination with fresh or frozen-thawed semen at a natural or synchronised oestrus. Animal Reproduction Science 84, 359-368.

Fisher MW (2004) A review of the welfare implications of out-of-season extensive lamb production systems in New Zealand. Livestock Production Science, 85 (2-3): 165-172.

Gürsoy O, Kırk K, Pollott GE (1998) Progeny testing for milk yield in Turkish Awassi sheep. 6th World Congress on Genetics Applied to Livestock Production, 12-16 Jan 1998. Armidale- Australia 24: 137-140.

Gürsoy O, Kırk K, Pollott GE (2001) İvesilerin Seleksiyonla Süt Verimlerinin Islahı. Proje No: VHAG-1294 Kesin Sonuç Raporu TÜBITAK, Mayıs 2001. Ankara- Türkiye.

Halbert GW, Dobson H, Walton JS, Sharpe P, Buckrell BC (1990) Field evaluation of a technique for transcervical intrauterine insemination of ewes. Theriogenology. 33(6): 1231 - 1243.

Kaymakçı M, Sönmez R (1989) Türkiye'de Koyunlarda Verimliliği Arttırmanın Başlıca Yolları, Hayvansal Üretim Dergisi. 32: 1-13.
Kırk K (1994) Ceylanpınar Tarım İşletmesi İvesi Populasyonunda Bazı Dölerme Özellikleri, Yapay Tohumlama Uygulamaları ve Farklı Sperma Dozlarının Etkileri. Ç.Ü. Fen Bil. Enst., Yüsek Lisans Tezi, Kod No: 871. 1994. Adana- Türkiye.

Kırk K, Gürsoy O (1995). Reproductive Performance of Awassi Ewes With Artificial Insemination Using Fresh Semen. Regional Symposium on:Integrated Crop Livestock System in The Dry Areas of West Asia and North Africa. 292-299. Improvement of CropLivestock Integration Systems in West Asia and North Africa ed.N.Haddad, R.Tutwiler and E.Thomson. 6-8 November 1995. Amman- Jordan.

Kırk K, Gürsoy O (1998) İvesilerin Yapay Tohumlamaya Yönelik Dölerme Özellikleri. V.Ulusal Nükleer Tarım ve Hayvancılık Kongresi, 440-444. 20-22 Ekim 1998. Konya/ Türkiye.

Kırk K (2018) Breeding local dairy sheep production on Van province. Zootekni Federasyonu, 10th International Animal Science Conference Book. p. 159. 25-27 October, Antalya/Turkey.

Kingwell RS, Abadi Ghadim AK, Robinson SD, Young JM (1995) Introducing Awassi Sheep to Australia: an Application of Farming System Models. Agricultural Systems 47 (45): 1471.

Milán MJ, Caja G, González-González R, Fernández-Pérez A $M$, Such X (2011) Structure and performance of Awassi and Assaf dairy sheep farms in northwestern Spain. J. Dairy Sci. 94:771-784.

Paulenza H, Soderquist L, Adnøy T, Soltund K, Sæthere PA, Fjells $\varnothing$ ye KR, Andersen Bergb K (2005) Effect of cervical and vaginal insemination with liquid semen stored at room temperature on fertility of goats. Animal Reproduction Science 86: 109-117.

Paulenza H, Soderquistb L, Tormod DT, Ove Harald Fossend $\mathrm{OH}$, Berge KA, (2003) Effect of milk- and TRIS-based extenders on the fertility of sheep inseminated vaginally once or twice with liquid semen. Theriogenology 60: 759-766.

Pollott GE, Gürsoy O, Kırk K (1998) Genetics of milk and meat production in Turkish Awassi sheep. 6th World Congress on Genetics Applied to Livestock Production, 12-16 Jan 1998. Armidale- Australia. 24: 177-180.

Santolariaa P, Vicente-Fiel S, Palacína I, Fantova E, Blasco ME, Silvestrec MA, Yániz JL (2015) Predictive capacity of sperm quality parameters and sperm subpopulations on field fertility after artificial insemination in sheep. Animal Reproduction Science 163: 82-88.

SAS (2014) Statistical Analysis System. SAS Institute Inc., Cary, N.C.USA.

Wulster-Radcliffe MC, Wang S, Lewis GS (2004) Transcervical artificial insemination in sheep: effects of a new transcervical artificial insemination instrument and traversing the cervix on pregnancy and lambing rates. Theriogenology, 2004 Sep 15; 62(6):990-1002. 
